\title{
Recent research progress in hybrid fiber-optic in-building networks
}

\author{
A.M.J. Koonen ${ }^{1}$, H. Yang ${ }^{1}$, H.-D. Jung ${ }^{1}$, Y. Zheng ${ }^{1}$, J. Yang ${ }^{1}$, H.P.A. van den Boom ${ }^{1}$, E. Tangdiongga ${ }^{1}$ \\ ${ }^{1}$ COBRA Institute, Eindhoven University of Technology, Den Dolech 2, NL 5612 AZ Eindhoven, The Netherlands \\ Phone: +31 40 2474806, Fax: +31 40 2455197, Email: a.m.j.koonen@tue.nl
}

\begin{abstract}
Advanced optically-emulated X-QAM techniques and the modal dispersion-robust radio-over-fiber OFM technique enable the delivery of high-capacity data via a single multimode (silica or polymer) optical fiber in-building network to wired as well as wireless terminals.
\end{abstract}

\section{Introduction}

With fiber-to-the-home techniques getting installed in ever more access networks, real broadband connectivity is finally getting to the doorstep of the subscriber's home. The next challenge is to extend this broadband connectivity to the service terminals inside his home. Today, there are separate in-home networks for the various services, such as twisted pair for telephony, coaxial cabling for video, and CAT-5 cabling and wireless LAN for data. Similarly as happens in access networks, it is preferable when there is a converged inhome network able to carry all existing and yet-to-come services together. This facilitates the upgrading of services and the introduction of new ones, and minimizes installation and maintenance costs. The inhome network infrastructure should be able to support both broadband and narrowband services, for delivery to both wired and wireless terminals. It should therefore be transparent for all kinds of signal formats.

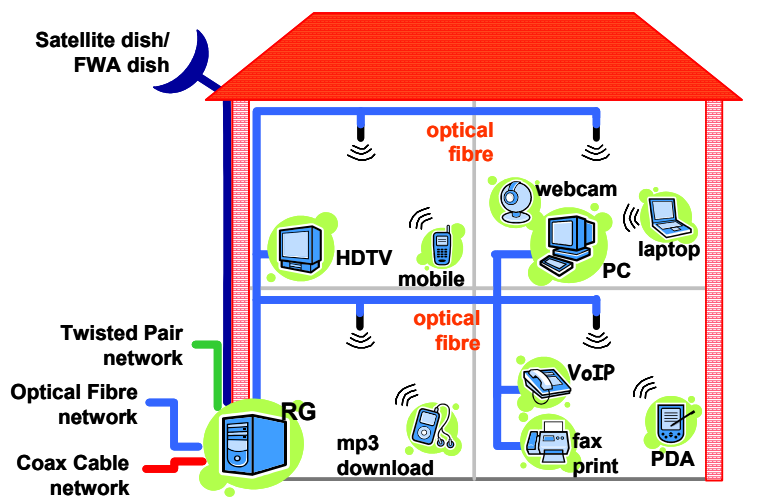

Fig. 1 Converged in-home network using optical fiber

As shown in Fig. 1, an optical fiber in-home network can excellently meets these demands. Multimode fiber (MMF) is most suited, as its larger core makes splicing, connectorizing and connection to the terminals easier and thus cheaper. In particular polymer optical fiber (POF) is more attractive than a silica one, as notwithstanding its very large core diameter it offers easy bending, plus do-it-yourself splicing and connectorizing. However, a $1 \mathrm{~mm}$ core diameter stepindex polymer fiber has a very high modal dispersion, and thus very limited bandwidth. In general, to overcome the modal dispersion in multimode fiber requires advanced signal processing techniques in order to carry high-speed data to wired terminals, and to carry microwave signals in radio-over-fiber pico-cell system architectures for delivery of high data rates to wireless terminals.

In this paper, some of our recent research results are reported regarding optical quadrature modulation techniques for high-capacity wired services, and regarding dynamically reconfigurable radio-over-MMF techniques for high-capacity wireless services.

\section{Optical Quadrature Amplitude Modulation}

Quadrature Amplitude Modulation (QAM) techniques enable to increase the information content per line symbol, and hence to reduce the bandwidth needed to carry a high data rate stream. QAM techniques are commonly used in wireless LANs and in cable modems, where the QAM signals are modulated on a single or on multiple (OFDM) carriers. Applying 64- and 256-QAM modulation at symbol rate of 1.8 MBaud using 80 carriers, $1.008 \mathrm{Gbit} / \mathrm{s}$ transmission over $100 \mathrm{~m} 1 \mathrm{~mm}$ core step-index PMMA POF has been achieved using a 650nm DVD laser diode [1]. Alternatively, the in-phase and quadrature-phase QAM components may be modulated in baseband on two separate wavelength channels, without needing a high-frequency carrier [2]. Thus the requirements on the bandwidth of the fiber link are lower, allowing highly dispersive fiber such as $1 \mathrm{~mm}$ core diameter step-index POF.

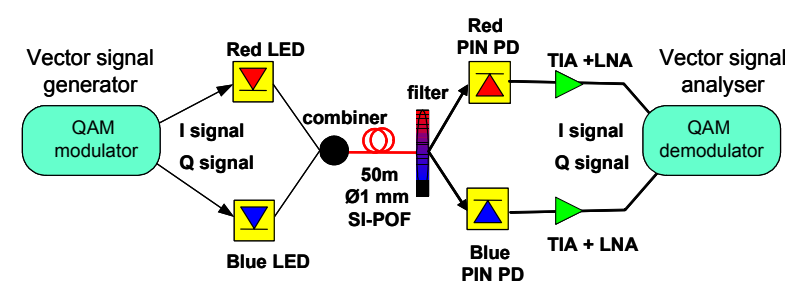

Fig. 2 Wavelength-emulated QAM

Fig. 2 shows an experimental setup using a red $650 \mathrm{~nm}$ and blue $460 \mathrm{~nm}$ LED, emitting $2.1 \mathrm{~mW}$ and $8.1 \mathrm{~mW}$ respectively, and modulated with respectively the I and Q components of a 25 MBaud 16-QAM data stream, carrying $100 \mathrm{Mbit} / \mathrm{s}$. After transmission over 50 meters of $1 \mathrm{~mm}$ core step-index PMMA POF, and wavelength demultiplexing, the I and Q components were fed to the 
QAM demodulator. The obtained Error Vector Magnitude (EVM) was $9.1 \%$, implying a BER $<10^{-5}$. The reach of this system can be further improved by using a green 520nm LED instead of the red 650nm LED, thus lowering the PMMA POF losses. Further improvements can be reached by linearization of the LEDs, and optimizing the I-Q channel phase matching.

\section{Reconfigurable radio-over-MMF}

The Optical Frequency Multiplying (OFM) technique is a radio-over-fiber technique which is capable of overcoming the modal dispersion in multimode fiber links, and at the same time of delivering an extremely pure microwave carrier to a simplified antenna station while only needing moderate-speed electronics at the central station [3]. Basically, by sweeping the optical frequency of a laser diode, intensity-modulating this signal with the data, and subsequently generating multiple harmonics of that sweep frequency in an FM-toIM converting periodic optical filter, at the antenna station a higher harmonic can be selected and thus a modulated microwave carrier is generated; see Fig. 3. Using a sweep frequency of $6.4 \mathrm{GHz}$, and selecting the $6^{\text {th }}$ harmonic, a $38.4 \mathrm{GHz}$ carrier has been generated with very small linewidth $(<100 \mathrm{~Hz})$. The robustness against modal dispersion was shown by successful delivery of an $120 \mathrm{Mbit} / \mathrm{s} 64-\mathrm{QAM}$ signal at $17.2 \mathrm{GHz}$ over $4.4 \mathrm{~km}$ of $50 \mu \mathrm{m}$ core silica graded-index fiber, with $\mathrm{EVM}<4.8 \%$.

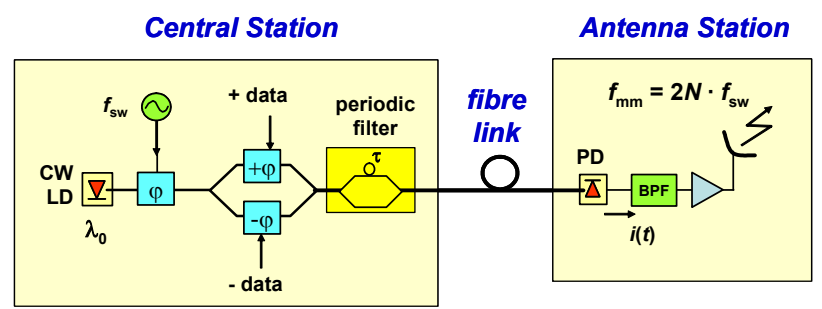

Fig. 3 Optical Frequency Multiplying

With the OFM technique in combination with flexible wavelength routing, in the various rooms of a building pico-cells for broadband wireless communication can be remotely created. As shown in Fig. 4, by means of a centralized transparent optical crossconnect, reconfigurable interconnections can be made between these pico-cells, thus creating reconfigurable virtual private wireless networks between rooms.

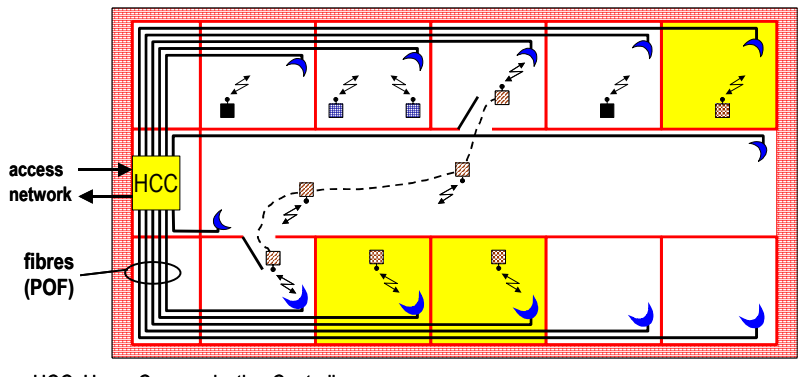

HCC: Home Communication Controller

Fig. 4 Reconfigurable inter-room wireless communication
Fig. 5 shows a radio-over-MMF system experiment with three-wavelengths $(1304 \mathrm{~nm}, 1310 \mathrm{~nm}, 1315 \mathrm{~nm})$, using add/drop multiplexers which provide the antenna stations with a selected wavelength carrying a $120 \mathrm{Mbit} / \mathrm{s}$ 64QAM signal at $23.7 \mathrm{GHz}$ [4]. The add/drop multiplexers were made with fiber Bragg gratings (FBG) made in $50 \mu \mathrm{m}$ core silica fiber and MMF optical circulators.

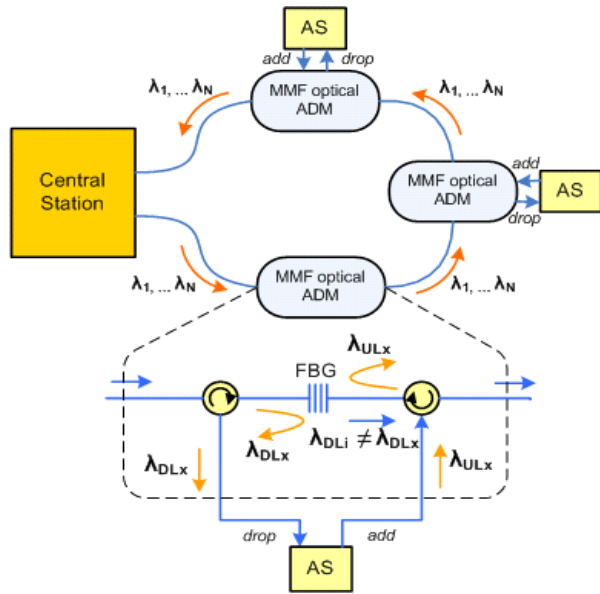

Fig. 5 Wavelength-routed radio-over-MMF

\section{Conclusions}

Using $\mathrm{x}$-level QAM advanced signal modulation formats, and the modal-dispersion robust OFM radioover-fiber technique, high-capacity data can be delivered via a converged multimode (polymer or silica) optical inbuilding network to both wired and wireless terminals.

\section{Acknowledgement}

Funding from the European Commission in the FP6 POF-ALL project and in the FP7 ALPHA project, and from the Dutch Ministry of Economic Affairs in the IOP GenCom Future Home Networks project is gratefully acknowledged.

\section{References}

[1] S. Randel, S.C. Lee, B. Spinnler, F. Breyer, H. Rohde, J. Walewski, A.M.J. Koonen, A. Kirstädter, "1 Gbit/s Transmission with $6.3 \mathrm{bit} / \mathrm{s} / \mathrm{Hz}$ Spectral Efficiency in a $100 \mathrm{~m}$ Standard $1 \mathrm{~mm}$ Step-Index Plastic Optical Fibre Link Using Adaptive Sub-Carrier Modulation", postdeadline paper Th4.4.1, Proc. ECOC 2006, Cannes, Sep. 24-28, 2006

[2] J. Yang, H.P.A. van den Boom, A.M.J. Koonen, "Wavelength multiplexed quadrature amplitude modulation for low cost high capacity data transmission over plastic optical fibre", Proc. POF2007, Torino, Sep. 10-12, 2007

[3] A.M.J. Koonen, M. García Larrodé, A. Ng'oma, K. Wang, H. Yang, Y. Zheng, E. Tangdiongga, "Perspectives of Radio over Fiber Technologies", Proc. OFC 2008, paper OThP3, San Diego, Feb. 24-28, 2008

[4] M. García Larrodé and A.M.J. Koonen, "All-Fiber FullDuplex Multimode Wavelength-Division-Multiplexing Network for Radio-Over-Multimode-Fiber Distribution of Broadband Wireless Services", IEEE Transactions on Microwave Theory and Techniques, Vol. 56, No. 1, pp. 248-255, Jan. 2008 